\title{
Editorial: Building Communities of Research
}

This issue gives a glimpse of some of the burning issues in childhood education. Authors discuss themes ranging from pre-school education, the transition from one phase in childhood education to the next, the ECD sector, and the education of teachers of young children.

In her extended literature review, which we include as the leading article, Fitzpatrick reviews the literature on school readiness and discusses the results. The editors selected this lengthy article because we believe that the literature she included in her research, with the detailed discussion, will be of use to the many new researchers in childhood education, and specifically foundation phase education. This review could also be of use to teacher education for the early grades, a topic that Dixon et al. researched from the side of lecturers for such programmes. Their article gives a glimpse of how mentoring can be seen to build a community of practice in teacher education, with lecturers from two universities building collaboration and support. This article is one of the first to be published in an important venture of the department of higher education and training (DHET) in which a critical mass of academics are nurtured to lead foundation phase teacher education in the future.

In each issue of this journal, we are bound to find articles on the teaching of mathematics and on children's learning. In her article, Graven gives a fresh view of the mathematics proficiency of learners in Grade 3. She describes how researchers are afforded the opportunity to investigate mathematics dispositions in depth at a 'maths club', making for truly interesting reading of the cases she describes.

When Stears and her co-authors investigate how teachers implement the science curriculum in the early years of schooling, they use a framework, which reminds one of Vygotsky's idea of a 'zone of proximal development' for individual learning. They utilise the notion of a 'zone of feasible innovation' to explore how teachers implement the science curriculum within, and integrated with other subjects of, the life skills curriculum. Not surprisingly they conclude that the 'innovation zone' of the teachers differ and that this task is challenging. Complementing the previous article, James and co-authors report on science learning in Grade $\mathrm{R}$ in three different school settings, showing that the teachers' knowledge of science, and the school contexts are the main variables in the type of science learning that is taking place in these schools.

Henning and Dampier report on a study of Grade 1 children's language competence, arguing that school discourse requires some stability and that young learners in classrooms where there is shifting language may experience unduly long periods of what anthropologists refer to as 'liminality'. This article wishes to contribute to the important debate on the medium of classroom communication in multilingual schools.

The last two articles in this issue take the reader to the vibrant world of ECD. Atmore, Van Niekerk and Ashley-Cooper's contribution to this issue is, like Fitzpatrick's an extensive source of review information that can be used by researchers in the ECD field. 
Van der Vyver's article shows how educational development work in ECD is always part of a much bigger picture in which not only financial sponsorship, but also community emancipation play a role in getting lay practitioners prepared for ECD practice that goes beyond mere day-care.

If the harvest of research articles in this issue is a sign of where the journal is heading, we will in due course be able to apply for inclusion in the Social Science Citation Index (ISI). Our application for accreditation in the DHET system was submitted in May and the results will be known by the end of the year.

Thank you to reviewers and authors who have, once again, offered their intellectual work to a journal that is waiting to be accredited. Should the submission by successful, we believe all the articles that are in the two issues this year will be eligible for subsidy.

Wishing you enjoyable reading.

Elizabeth Henning (Editor)

Graham Dampier, Hashina Ebrahim, Ronel Ferreira, and Shirley Pendlebury (Co-Editors) July 2012 